\title{
Elucidating the Mode of Action of Marine Natural Products through an Immunoaffinity Fluorescent (IAF) Approach
}

\author{
James J. La Clair, ${ }^{*, a}$ William Fenical ${ }^{*, b}$ and Leticia V. Costa-Lotufo ${ }^{*, c}$ \\ ${ }^{a}$ Department of Chemistry and Biochemistry, University of California at San Diego, 92093 La Jolla-CA, USA \\ ${ }^{b}$ Center for Marine Biotechnology and Biomedicine, Scripps Institution of Oceanography, \\ University of California at San Diego, 92093-0204 La Jolla-CA, USA \\ ${ }^{c}$ Departamento de Farmacologia, Instituto de Ciências Biomédicas, Universidade de São Paulo, \\ 05508-900 São Paulo-SP, Brazil
}

\begin{abstract}
Understanding the target and mode of action (MOA) of small molecules activity has become a critical feature in guiding the transition between drug discovery and clinical evaluation. While classically placed at the latter stages of a discovery program, we now describe how addressing the mode of action of natural products at the early stages of a program provides an important vehicle to inform the drug discovery process. In this review, we outline a streamlined cellular and molecular biological system and explore its utility through a series of four cases studies. We believe that this approach offers critical lessons to guide future drug discovery programs.
\end{abstract}

Keywords: marine natural product, mode of action, drug discovery, target identification, confocal microscopy

\section{Introduction}

Throughout history, natural products have played a key role in the treatment of human diseases. ${ }^{1}$ Even today, they are directly or indirectly responsible for a significant number of new drugs. ${ }^{2}$ Microbial natural products have played a particularly important role in the lead discovery accounting for the majority of antibiotic, anticancer, and anticholesterol drugs. ${ }^{3}$ While broadly useful, their application to cancer has provided countless individuals with effective therapeutic options. As a resource, they have provided a dual role of identifying new structural motifs for drug discovery efforts ${ }^{4}$ as well as identifying and validating new targets. ${ }^{5}$ While first discovered through cytotoxicity screening, it is apparent that successful treatments will rely on the co-discovery of associated biomolecular targets that offer selectivity and enhanced safety. However, there is an immediate need to develop methods that reduce the time associated with mode of action (MOA) and mechanisms of natural product activity. ${ }^{6}$

This review describes an approach that we have adopted over the last decade for lead discovery. Here, we have identified the importance of conducting natural product

*e-mail: jlaclair@ucsd.edu,wfenical@ucsd.edu, costalotufo@usp.br isolation, structural elucidation, and MOA studies, as parallel steps in the drug discovery program. Our efforts began through the development of a streamlined system that allows one to correlate cellular and biomolecular analyses into one process. Using four examples, we demonstrate how this so called immunoaffinity fluorescence (IAF) approach can be used to elucidate the molecular target and subsequently define the MOA of a new structural entity.

\section{Results and Discussion}

Early on we focused our efforts on developing a system that combined both cellular and molecular biological methods into the target identification-MOA evaluation process. Our work began by identifying a fluorescent tag that could be used to label a wide variety of natural products. In 2006, we published a description of this tool ${ }^{7}$ by illustrating how a blue fluorescent 4-dimethylamino4-coumarinacetic acid, later known as an IAF tag, could be installed on a wide array of natural products and used to differentiate their subcellular trafficking and localization. Soon thereafter, we turned our attention to establishing tools to link a natural products phenotypic cellular response and subcellular localization with its molecular targets. 


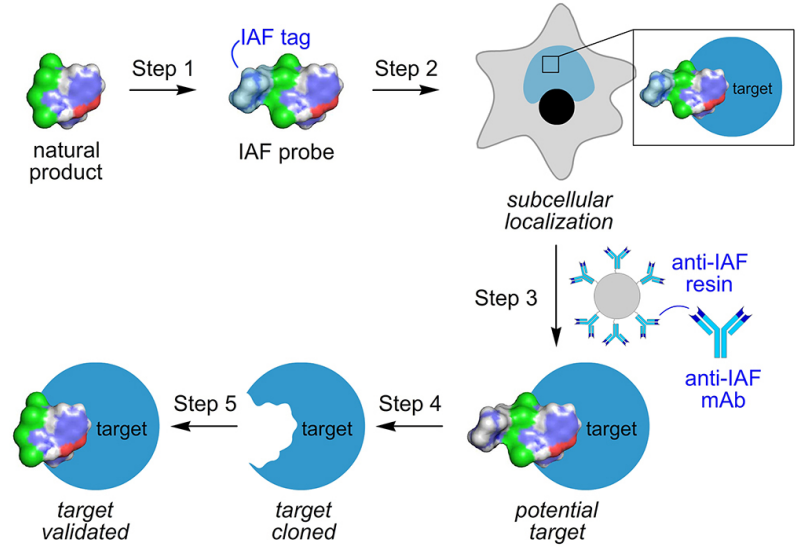

Figure 1. The IAF approach. A five-step procedure is used that begins with (Step 1) labeling a natural product with an IAF tag (shaded in light blue). Step 2: the uptake and cellular tracking of the probe is then explored using a combination of confocal and super-resolution microscopies. Once the subcellular localization and trafficking is understood, samples of cell lysates are prepared from these cells or their subcellular fractions. Step 3: the targets within these lysates are then isolated using an immunoprecipitation (IP) technique that applies monoclonal mAbs designed against the IAF tag as a tool to selectively isolate proteins or other biomolecules that bind to the natural product. Step 4: the identity of the immunoprecipitated biomolecules is then elucidated. For proteins, this is accomplished using a combination of SDS-PAGE purification and trypsin-digest liquid chromatography-mass spectrometry (LC-MS/MS) protein ID and MudPIT analyses. Step 5: if a protein target is found, it is cloned, expressed and purified and used to (Step 6) validate binding to the natural product. We find that nano-isothermal titration calorimetry (ITC) offers an ideal means to complete these studies. For low molecular weight proteins, we have also found that nuclear magnetic resonance (NMR) titration methods using either unlabeled or ${ }^{15} \mathrm{~N}$-labeled protein also provide effective identification of binding events.

Next, we developed an antibody against the IAF tag. Through the assistance of Stefan Andersson, then at UT Southwestern, we prepared a panel of monoclonal antibodies (mAbs) XRI-TF01 to XRI-TF42 that demonstrated potent and selective binding to IAF epitope. We then carefully characterized the ability of selectively identify labeled proteins in cell lysate. ${ }^{8}$ After careful validation, we found one mAb, XRI-TF35, offered complete selectivity for the IAF epitope over a series of mammalian, fungal and bacterial cell lysates. Using a combination of flow cell and conventional hybridoma methods, we have produced gram quantities of this $\mathrm{mAb}$ at high purity for diverse MOA studies.

The following sections provide an overview of some of the applications of this IAF approach. The first study describes an application to the ammosamide natural products. ${ }^{9}$ Here, we used an early version of this system to identify the cellular, subcellular, and molecular selectivity of the ammosamides, directly in parallel with its isolation, structure elucidation and chemical synthesis. ${ }^{10,11}$ The second case study explores an extension of the IAF approach to monitor protein natural product interactions through the transfer of an IAF tag from the natural product to its<smiles></smiles>

ammosamide $A(X=S)$ ammosamide $B(X=O)$

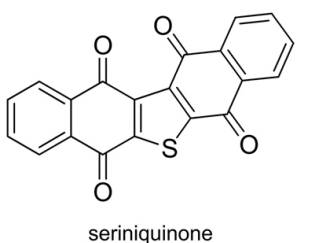

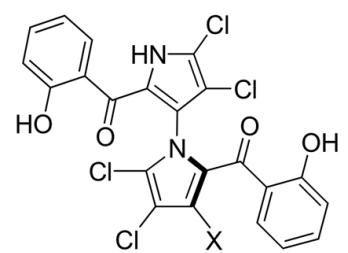

marinopyrrole $A(X=H)$

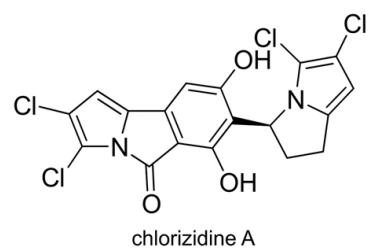
marinopyrrole $B(X=B r)$

Figure 2. Structures of four marine natural products examined using the IAF approach.

protein target upon binding. ${ }^{12}$ In this study, we demonstrate how this 'tag-transfer' concept works through studies on the marinopyrrole natural products. ${ }^{13,14}$ The final two case studies on the seriniquinone ${ }^{15}$ and chlorizidine ${ }^{16,17}$ natural products define how further extension into downstream and cell cycle markers allows one to develop a streamlined connectivity between cellular processing, its associated molecular targets, and ultimate downstream effects.

\section{Case Study 1: The Ammosamides Target Myosin}

Our first example arose from an initiative developed in the Fenical laboratory to explore microbes obtained from marine sediments. ${ }^{18}$ As part of this program, Streptomyces strain CNR698 was isolated from bottom sediments collected at a depth of 1,618 meters in the Bahamas Islands in 2003..$^{10}$ Cytotoxicity-guided isolation, using the HCT-116 cell line, and fractionation by C18 flash chromatography and reversed-phase high-performance liquid chromatography (RP-HPLC) purification led to the isolation of ammosamides A and B (Figure 2), as blue and red solids, respectively. Elucidation of their structures proved to be particularly difficult due to their inherent insolubility and a lack of descriptive proton (nuclear magnetic resonance) NMR signals, ultimately requiring the integration of NMR spectral analysis, mass spectrometry data, and single crystal X-ray diffraction studies. ${ }^{10}$

Our MOA studies began by installing the IAF tag onto the ammosamide core. ${ }^{9}$ Using ammosamide $\mathrm{B}$, we were able to prepare a single labeled product (Figure 3) with highregioselectivity. We then turned to time course imaging to screen and identify the appropriate concentration and time for image collection. Using this data, we collected a series of images depicting the subcellular localization and trafficking 


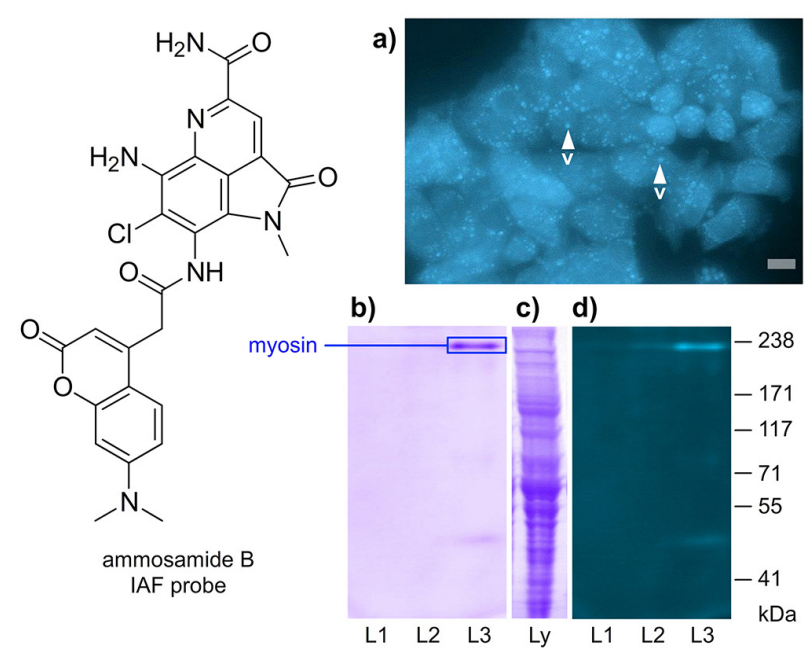

Figure 3. Application of the IAF approach to elucidate the targeting of myosin by ammosamide B. (a) An image from $10^{6} \mathrm{HeLa}$ cells incubated with $1 \mathrm{~mL}$ of $50 \mu \mathrm{M}$ ammosamide B probe in Dulbecco's Modified Eagle's Medium (DMEM) after incubation at $37^{\circ} \mathrm{C}$ for $12 \mathrm{~h}$; (b-d) immunoprecipitation studies; (b) a 3-8 \% tris-acetate SDS-PAGE gel stained with GelCode arising from the IP of lysate from $10^{8}$ HCT- 116 cells treated with the ammosamide B probe and Affigel $\mathrm{Hz}$ resin containing $12.5 \mathrm{mg} \mathrm{mL}^{-1}$ of XRI-TF35 $\mathrm{mAb}$. After incubation for $12 \mathrm{~h}$ and multiple washings with PBS pH 7.2 at $4{ }^{\circ} \mathrm{C}$, the bound protein was eluted from XRI-TF35-Affigel $\mathrm{Hz}$ resin with $0.1 \mathrm{M}$ Tris- $\mathrm{HCl} \mathrm{pH} 6.8$ (L1), $5 \mathrm{mM}$ ammosamide B probe in $0.1 \mathrm{M}$ Tris- $\mathrm{HCl} \mathrm{pH} 6.8$ (L2), or $50 \mathrm{mM}$ ammosamide B probe in $0.1 \mathrm{M}$ Tris- $\mathrm{HCl} \mathrm{pH} 6.8$ (L3) at $23{ }^{\circ} \mathrm{C}$; (c) HCT-116 lysate stained with GelCode blue; (d) a fluorescent image of the gel in (b) prior to GelCode blue staining. Box denotes protein bands identified through trypsin-digest LC-MS/MS as a member of the myosin family (adapted from reference 9).

of the ammosamide B probe in live mammalian cells. Upon addition, the probe concentrated into HeLa, HCT-116, and PC-3 cells within minutes (Figure 1). After $12 \mathrm{~h}$ of incubation, the blue fluorescence from the probe was observed in vesiculated regions (Figure 1a). Using counterstains, we were able to identify these regions as lysosomes.

In parallel, immunoprecipitation studies were conducted from lysates from HCT-116 using Affi-gel resin bearing the $12.5 \mathrm{mg} \mathrm{mL}^{-1}$ of the anti-IAF XRI-TF35 mAb. Over multiple repetitions, we observed a band at approximately $220 \mathrm{kDa}$, which when submitted to liquid chromatographytandem mass spectrometry (LC-MS/MS) protein ID analysis revealed a protein most similar to those in the myosin family, with $22-28 \%$ coverage of the amino acid residues. Subsequently in vitro labeling studies of an authentic sample of myosin II with the probe along with further confocal microscopic studies not only validated the targeting of myosin but suggested that exposure to ammosamide B and its associated IAF probe delivered hyperfragmented actin fibers and unassembled clusters of microtubules. Overall these observations, as well as the translation of the probe over time into lysosomes, were consistent with a loss of myosin function. Further, histological analyses demonstrated that this targeting was not limited to skeletal muscle, indicating that it likely interacts with several of the myosin families. ${ }^{9}$

Since these studies, a series of manuscripts have described the identification of new members of the ammosamide family, ${ }_{19}$ as well as the establishment of effective methods for their chemical synthesis. ${ }^{11,20}$ Now, we believe that the parallel development of natural product isolation with target identification-MOA studies provides a superior platform for establishing new small molecule motifs with key biological activities. As demonstrated through this study, we were able in a short time to rapidly correlate new small molecule structure with a new function.

\section{Case Study 2: The Marinopyrroles Target Actin}

Our second study began with an actinomycete strain CNQ418, obtained from a sample of marine sediment collected near La Jolla, CA, USA, at a depth of $51 \mathrm{~m}$. Cultivation of this strain in a seawater-based medium for 7 days, followed by solid-phase extraction of the broth using Amberlite resin and fractionation on silica gel and final purification using $\mathrm{C} 8$ reversed-phase HPLC resulted in the isolation of marinopyrroles A and B (Figure 2).${ }^{13}$ These compounds were analyzed for the molecular formulas $\mathrm{C}_{22} \mathrm{H}_{12} \mathrm{Cl}_{4} \mathrm{~N}_{2} \mathrm{O}_{4}$ and $\mathrm{C}_{22} \mathrm{H}_{11} \mathrm{BrCl}_{4} \mathrm{~N}_{2} \mathrm{O}_{4}$, respectively. The structures of these rotationally chiral molecules were elucidated by a combination of 2D NMR studies and X-ray crystallography. With structures at hand, we then turned our effort to explore their target identification and associated MOA in HCT- 116 cells. ${ }^{12}$ While only moderately cytotoxic, we were interested in exploring if these materials targeted pathways that may not be directly related with cell death phenotypes.

One of the most enjoyable facets of collaborative studies arises from the unique viewpoint that comes from the assemblage of a new team of individuals. In 2008, we began discussing the concept of using the IAF tag as a tool to mark a potential natural product binding protein. After evaluating several potential natural products, our attention focused on a recently isolated natural product the marinopyrroles. Chambers Hughes in the Fenical laboratory began by preparing an IAF probe from marinopyrrole A. ${ }^{12}$ Here, we used prior data that indicated the fully acetylated marinopyrrole A could be made and maintained activity, as a guide for our choice in IAF labeling. Using established synthetic protocols and detailed NMR characterization, ${ }^{7,14}$ we were able to prepare both a mono-labeled and di-labeled probe, as shown in Figure 4. We then returned to cell line screens and validated that the mono-labeled probe 
maintained its bioactivity with an average $\mathrm{GI}_{50}$ value of $1 \mu \mathrm{M}$, a value that was ca. 10 -fold more active than its parent natural product, marinopyrrole A.

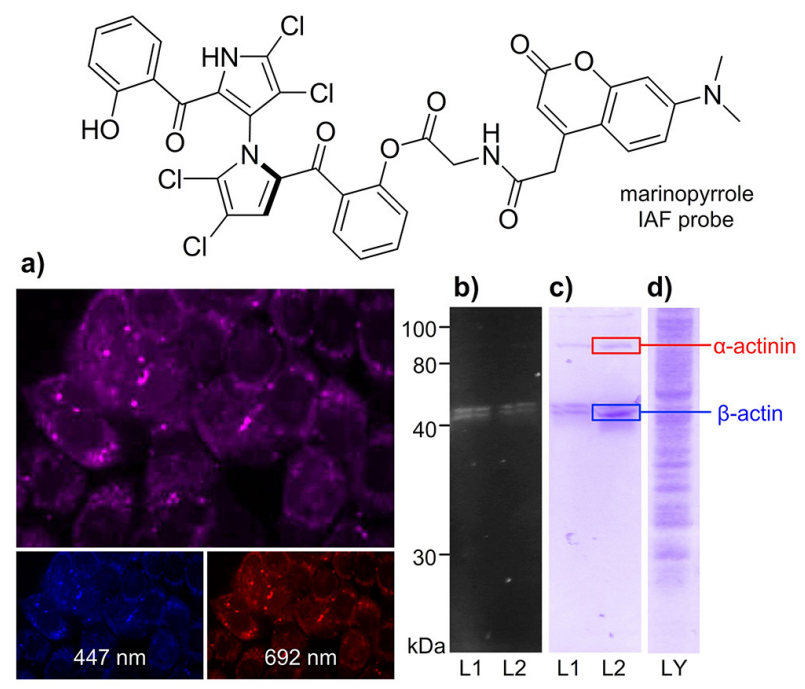

Figure 4. Application of the IAF approach to elucidate the targeting of actin by marinopyrrole A. (a) Confocal fluorescent images of HCT-116 cells depicting the red and blue fluorescence from the uptake of $10 \mu \mathrm{M}$ marinopyrrole A IAF probe after $6 \mathrm{~h}$. A set of confocal fluorescent images showing blue $(447 \mathrm{~nm})$, red $(692 \mathrm{~nm})$, and two-color mixed channel (mix) with the blue arising from the IAF tag and the red from the marinopyrrole motif; (b) a fluorescent SDS PAGE gel showing cell lysate obtained from HCT-116 cells $\left(10^{8}\right.$ cells) treated with $10 \mu \mathrm{M}$ the marinopyrrole IAF probe in $\mathrm{L} 1$ and $10 \mu \mathrm{M}$ of a related IAF probe ${ }^{12}$ in L2 for $12 \mathrm{~h}$; (c) a Silver Blue stained SDS-PAGE gel depicting proteins immunoprecipitated from the lysate in (b) using Affigel 10 resin containing $3.5 \mathrm{mg} \mathrm{mL}^{-1}$ of an anti-IAF antibody XRI-TF35; (d) SDS-PAGE gel depicting the HCT-116 cell lysate used in (c). Proteins were identified by Trypsin-digest LC-MS-MS analysis as indicated by red and blue boxes (adapted from reference 12).

Using two-color confocal microscopy, we compared the native red fluorescence from marinopyrrole $\mathrm{A}$ to the blue fluorescence from the IAF tag in the associated IAF probe (Figure 4a). The presence of a similar pattern of red and blue staining confirmed that IAF tag (blue) and marinopyrrole motif (red) shared the same subcellular localization in HCT- 116 cells, and therefore, the IAF probe provided an excellent and stable mimic of marinopyrrole A.

Using HCT-116 cells, we applied the immunoprecipitation (IP) protocol and identified two fluorescent bands at 40-45 $\mathrm{kDa}$ and a higher band at ca. $85 \mathrm{kDa}$ (Figures $4 \mathrm{~b}-4 \mathrm{c}$ ), which are apparent in the crude lysate (Figure 4d). Mass spectral analysis indicated that the two lower bands were actin, while the upper band arose from actinin. The fact that actinin was observed during IP experiments in the lysate, while not fluorescent, is expected given its tight complexation with actin. ${ }^{21}$

After validation using purified proteins, we collaborated with the Dorrestein laboratory at UC San Diego to identify the site of dye transfer to actin. IAF labeled protein from the IP fractions were trypsin digested, purified by HPLC based on the absorbance of the IAF dye at $350 \mathrm{~nm}$, and subjected to linear ion trap tandem mass spectrometer (LTQ-MS/MS) with a NanoMate direct infusion system. Evaluation of the resulting spectra using the proteomics search tool, InSpecT, to find peptides that were modified by the IAF tag $(\mathrm{M}+286 \mathrm{Da})$, resulted in the identification of peptide $\mathrm{V}_{98}$ APEEHPTLLTEAPLNPKANR $_{118}$. Further evaluation of the MS2 fragment ions observed enabled us to localize the site of modification to Lysine K115, a distinct site on actin that neither overlaps the ATP, gelsolin, and profilin binding site $^{21}$ nor overlaps with the pocket targeted by other known natural products such as latrunculin. ${ }^{22}$ This investigation provides definitive support for the use of the IAF approach along with a tag transfer protocol ${ }^{23}$ for MOA studies.

Since these studies, recent access to materials through total synthesis ${ }^{24}$ has enabled further explorations into the MOA of the marinopyrroles. These studies included evidence that marinopyrrole A, inappropriately renamed as martioclax, showed significant decrease in Mcl-1 expression along with Mcl-1 degradation via the proteasome system, which was associated with its pro-apoptotic activity. ${ }^{25}$ While these studies suggested that marinopyrrole A may act as an Mcl-1 inhibitor, early validation efforts failed to identify cytotoxicity of the natural marinopyrrole A in Mcl-1 dependent cell lines with the exception of leukemia cells. ${ }^{26}$

More recently, a series of target-guided screening and SAR programs have identified ligation of Mcl-1, indicating that indeed marinopyrrole A binds to Mcl- $1 .{ }^{27}$ However, the targeting of Mcl-1 was not observed by others through use of additional models including the screening of cell lines with altered Mcl-1 expression. ${ }^{28}$ It should be emphasized that marinopyrrole is a potent electrophile that readily adds nucleophilic residues in proteins by displacement of chlorine.${ }^{14}$ Hence, it is quite clear that marinopyrrole can target many different intracellular proteins. While ongoing studies continue to define a detailed model describing the connection between targets and MOA of the marinopyrroles, one must also realize that few if any natural products interact with a single protein within a living organism. This observation offers an important lesson for natural product chemical biology and drug discovery. First, many natural products do not have only one target, and as evidence now begins to suggest, the marinopyrroles do not. Second, the target selectivity often arises from the specific cell line or model used. Third and perhaps most importantly, not all targeting results in a downstream phenotypic response, and detailed pathway analyses are required before one can claim a selective function. All to often, the failure to carefully evaluate multiplicity in targets 
leads to insurmountable problems during the translational process into the clinic, and suggests an important factor in avoiding the overstatement of target selectivity.

\section{Case Study 3: Seriniquinone Targets DCD}

Our third study began by exploring novel metabolites from a panel of Gram positive marine bacteria. ${ }^{29}$ As part of this program, we identified seriniquinone (Figure 2), molecular formula $\mathrm{C}_{20} \mathrm{H}_{8} \mathrm{O}_{4} \mathrm{~S}$, isolated from culture broths of a rare marine bacterium of the genus Serinicoccus. ${ }^{15}$ The structure of seriniquinone was deduced using chemical and spectroscopic methods and by comparison with a synthetic sample which had been reported as part of a materials science program. ${ }^{30}$ Our interest in seriniquinone began after observing significant selectivity in melanoma (eight of nine cell lines screened) along with potent activity in a unique selection of other cell lines. ${ }^{15}$

Confocal microscopic analysis of seriniquinone indicated that the compound localized in the endoplasmatic reticulum (ER) (Figure 5a), co-localizing with ER tracker blue-white, during the initial hours of treatment. However, after several hours seriniquinone showed accumulation in the autophagosomes, co-localizing with monodansylcadaverine (Figures $5 \mathrm{~b}$ and $5 \mathrm{c}$ ). ${ }^{15}$ Analysis of cell death biomarkers suggested the treated cells underwent autophagy followed by apoptosis. The link between these processes has been discussed, ${ }^{31}$ and although autophagy is typically seen as a survival mechanism, eliminating damaged protein and organelles through lysosomes digestion, it can excessively degrade the cytoplasm, triggering cell death, generally involving apoptosis effectors.

The next challenge was to determine the targets of seriniquinone (Figure 2). This began with preparation of a seriniquinone probe (Figure 5) through chemical synthesis. After validation of the probes activity with confocal microscopy and bioactivity analyses, we turned to the IP protocol to screen for its biomolecular targets. After several repetitions, the SDS-gel of the IP products always returned multiple protein bands from 10 to $250 \mathrm{KDa}$ (Figure 5d) that were recovered, trypsin digested and submitted to LC-MS/MS analysis. The results were quite intriguing since most of the bands presented sequences of a still poorly studied protein called dermcidin (DCD), together with other proteins such as HSP70 and GAPDH. The treatment of the samples with iodoacetamide broke the observed interaction of dermcidin and cellular proteins, and pointed to dermcidin as a molecular target for the anticancer natural product. The validation of DCD as the target of seriniquinone was further demonstrated using western blotting, with anti-DCD antibody, and qPCR, whereas an increasing expression of
DCD was observed upon seriniquinone treatment. The gene expression increase was much more evident in the most sensitive melanoma cell line, MALME-3M, confirming heightened activity in DCD expressing cell lines. ${ }^{15}$

Since the description of DCD in 2001 as an antimicrobial peptide, ${ }^{32}$ its involvement in cancer has gained increasing interest. The DCD gene product is actually proteolytic processed into small peptides, including a 30aa proteolysis inducing factor (PIF also called Y-P30) and a $47 \mathrm{aa}$ peptide DCD-1. It has been demonstrated that DCD is overexpressed in different cancer types, especially in breast cancer, where it was related to a poor prognosis. ${ }^{33,34}$

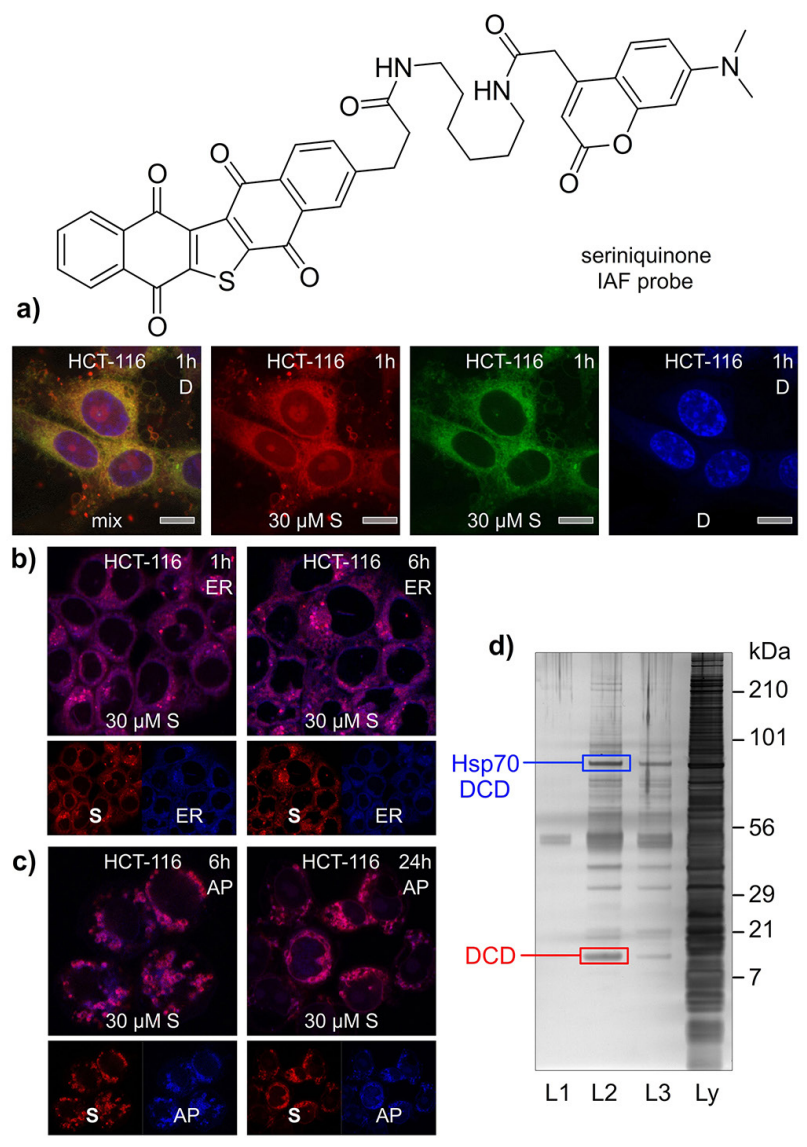

Figure 5. Application of the IAF approach to elucidate the targeting of dermcidin (DCD) by seriniquinone. (a) Fluorescence from treatment of HCT-116 cells with seriniquinone for $1 \mathrm{~h}$ results in the appearance of green-red fluorescence from around the nucleus, as indicated by counterstaining with DAPI (blue). Counterstaining of the (b) endoplasmic reticulum (ER) and (c) autophagosomes (AP) was used to validate the subcellular localization events. Images depict staining of cells with ER stain at 1 and $6 \mathrm{~h}$ and AP stain at 6 and $24 \mathrm{~h}$; (d) a silver-stained SDS PAGE gel depicting proteins immunoprecipitated from HCT-116 cell lysates treated with the seriniquinone IAF probe over $8 \mathrm{~h}$ at $4{ }^{\circ} \mathrm{C}$. This response was dose dependent with an increasing return of immunoprecipitated protein at higher concentrations of the seriniquinone IAF probe (L2 versus L3), but was not apparent in experiments lacking the probe (L1). Trypsin-digest LC-MS/MS analysis of the protein in a 90-kDa band returned peptides corresponding to DCD (red) and Hsp70 (blue) (adapted from reference 15). 
The hypothesis that DCD is actually binding to or covalently-modified by different cellular proteins to exert biological functions has been corroborated by others. ${ }^{35}$ For instance, its role in cell migration promoting prometastatic effects was supported by the binding and modulation of Nck1, a protein involved in the regulation of different tyrosine kinase receptors as PDGFR and EGFR, and also known to stimulate Rho GTPases Rac1 and cdc 42 activation, regulating cell adhesion, migration and gene transcription. ${ }^{35}$ Modulation of ERBB signaling pathways was suggested as the mechanisms of breast tumorigenesis. ${ }^{34}$ Whether the effects of DCD on cancer is related to Y-P30, DCD-1 or the whole DCD protein remains to be elucidated.

\section{Case Study 4: Chlorizidine A Targets Glycolysis}

Our final example began with isolation and characterization of a marine bacterium, Streptomyces sp. strain $\mathrm{CNH} 287 .{ }^{17}$ Cultivation of this strain a seawater-based medium followed by solid phase extraction with Amberlite XAD-18 resin and fractionation on silica gel resulted in one fraction with significant cytotoxicity against HCT-116 cells. Isolation by $\mathrm{C} 18$ reversed-phase HPLC, we were able to identify a cytotoxic metabolite, chlorizidine A (Figure 2), with a prominent UV-Vis profile. While the material proved to be sensitive to ambient conditions, we were able to prepare stable materials by acetylation. Here the resulting bis-acetylated product was readily handled without degradation. Using a combination of 2D-NMR and $\mathrm{X}$-ray crystallography, we were able to assign the structure of chlorizidine A, as shown in Figure 2. ${ }^{17}$

The targets and MOA of chlorizidin A were further analyzed using an IAF probe (Figure 6) in HCT-116 cells. ${ }^{16}$ Confocal microscopic analysis indicated that the probe was rapidly taken up in the cytosol, and after $10 \mathrm{~h}$ treatment, chlorizidine IAF probe (Figure 6) was observed in the lysosomes, as confirmed by its co-localization with LysoTracker red DND-99 (Figure 6c). Further characterization of the phenotypic effects of chlorizidine A and its bis-acetate derivative in HCT-116 cells, reinforced the cytostatic, rather than cytotoxic, effects of chlorizidine A. The bis-acetate derivative, which proved to be more active and stable, arrested treated cells during G1phase of the cell cycle. The IP studies, then, led to the isolation of 4 bands, two stronger ones, identified by LC-MS/MS as $\alpha$-enolase I (hENO1, $48 \mathrm{kDa}$ ) and $D$-glyceraldehyde-3-phospate dehydrogenase (GAPDH, $27 \mathrm{kDa}$ ), and two minor bands at 90 and $45 \mathrm{kDa}$, identified as HSP90 and actin, respectively. ${ }^{16}$

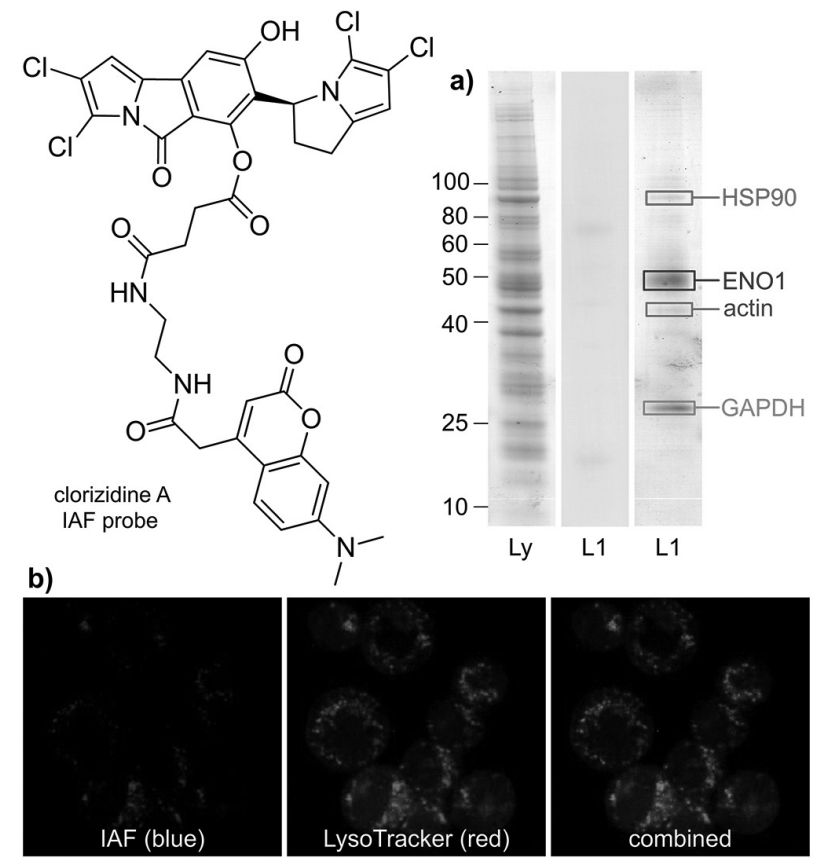

Figure 6. Application of the IAF approach to elucidate the targeting of glycolytic enzymes by chlorizidine A. (a) Immunoprecipitation of HCT-116 cell lysate (1 mg mL $\mathrm{m}^{-1}$ total protein) in PBS ( $\left.\mathrm{pH} 7.2\right)$ containing $10 \mu \mathrm{m}$ chlorizidine A IAF probe returned four distinct protein bands after staining with GelCode blue stain. Lanes L1-L3 depict HCT-116 cell lysate (L1), the IP fraction (L2) from the chlorizidine A IAF probe, and the IP fraction (L3) from an IAF control; (b) subcellular localization of the chlorizidine A IAF probe in HCT-116 cells. A confocal microscopy image depicting HCT-116 cells treated with $5 \mathrm{~mm}$ chlorizidine A IAF probe for $16 \mathrm{~h}$ and then co-stained with $2.5 \mathrm{~mm}$ LysoTracker Red DND-99 for 15 min before imaging. The appearance of violet in the combined image indicates the co-localization of blue from the chlorizidine A IAF probe and red from the LysoTracker Red DND-99. (adapted from reference 16).

Target validation was conducted by western blotting and isothermal calorimetry (ITC) studies using recombinantlyexpressed hENO1. First, the identification of the bands was confirmed using highly specific commercial mAbs to identified proteins, hENO-1, GAPDH, HSP90 and actin. The ITC analysis indicated that chlorizidine A binds to hENO1 protein with a stoichiometry of 1.4-1.6 molecules of the natural product to one enzyme, and a binding constant $\mathrm{Kd}$ of $1.9 \pm 0.9 \mu \mathrm{M}$. These findings suggested that the primary targets for chlorizidine A were the enzymes belonging to the glycolytic pathway, hENO1 and GAPDH, while the interactions with actin and HSP90 could be secondary or even nonspecific considering the nucleophilic nature of the C5 carbonyl in the chlorizidine A IAF probe. ${ }^{16}$

The reprogramming of energy metabolism in cancer cells is recognized as an important feature for tumor progression since the description of the "Warburg effect". ${ }^{36}$ Cancer cells are highly dependent of glycolytic pathways in spite of oxygen supply to keep their constant 
proliferative state, and this 'adaptive' condition raises from higher expression in key proteins such as glucose transporters GLUTs, and enzymes like GAPDH, ENO1, hexokinase II (HKII), lactate dehydrogenase (LDH) and phosphofructokinase (PFK-B). ${ }^{37}$ Hence, these proteins have been explored with some success as therapeutic targets for cancer treatment. ${ }^{38}$

\section{Conclusions}

Over the last decade, team efforts between our laboratories have developed and integrated a streamlined system that unites cellular methods such as fluorescence microscopies with molecular target elucidation strategies. Through the course of four case studies, we have demonstrated how this method can be applied to effectively deliver information regarding the cellular trafficking, subcellular localization and biomolecular targets of a given natural product. Within these examples, we illustrate the importance of cellular and molecular target validation and apply a compendium of tools including: colocalization studies, upstream and downstream marker analyses, cell cycle analysis, as well as biochemical methods such as isothermal calorimetry (ITC). While the IAF approach provides rapid information on cellular and molecular targetry, we have found that only after multiple point validation efforts can one confidently identify a specific biomolecule or pathway as a target. Additionally, without the use of critical downstream and upstream markers, it is also difficult to establish that identified targets are directly responsible for the observed phenotype.

Finally and perhaps most critically, we have learned that many natural products do not have a single specific biomolecular target, and in some cases the targets and phenotypes observed change according to the cell examined. It is within these variables that we see the need for the further development of optimized target elucidation techniques. Our program is currently exploring the development of more detailed tools that directly integrate genomic, epigenomic, proteomic, and metabolomics signals and apply these systems to elucidate the MOA in a more global sense. Here, we see expansion of these tools to identify and validate the selectivity of a natural product drug lead in terms of its cellular selectivity as given by screens such as the NCI's cancer cell line panel. We also find that the MOA of natural products also needs to be carefully evaluated with regards to the time of treatment. Here, we seek to inform at the level of time and use this information to further understand how natural products act and deliver their uniquely specific and timed biological activity.

\section{Acknowledgments}

This work was supported by the NIH, National Cancer Institute, under grant CA044848 (W. F.), Xenobe Research Institute (J. J. L.) and Brazilian National Council for Scientific and Technological Development, CNPq (L. V. C. L.).

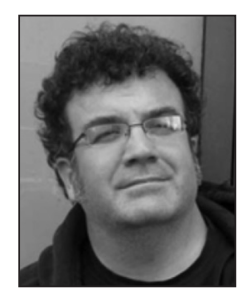

James J. La Clair (Jim) received his PhD degree in Chemistry from the State University at Buffalo under the tutelage of Peter T. Lansbury. His studies in organic chemistry continued through a postdoctoral fellowship with Gilbert Stork at Columbia University. He then undertook a collaborative position between the laboratories Richard Lerner at Scripps Research Institute and Manfred Eigen at the Max Planck Institute für Biophysikalische Chemie. In 1999, he went independent in order to focus his time on research applications and concepts. This has since included research scientist positions at UC San Diego, the Salk Institute among other collaborative endeavors. To date, his efforts have resulted in publications spanning a wide diversity of natural and physical sciences.

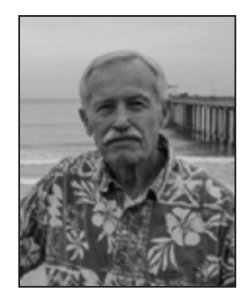

William Fenical (Bill) is distinguished professor of oceanography and pharmaceutical science at the Scripps Institution of Oceanography, University of California at San Diego. His career in marine natural products has spanned more than 45 years ever since his early work on the pigments of abalone shells. Fenical has more than 450 publications in marine natural products and 200 of these have involved developing the field of marine microbial chemistry. He is the recipient of the Paul Scheuer Award in Marine Natural Products Chemistry (1996), the International Society of Chemical Ecology's Silver Medal Award (1997), the Ernest Guenther Award in Natural Products from the American Chemical Society (2006). And, in 2008 Bill was Elected as Fellow of the American Association of Science (AAAS).

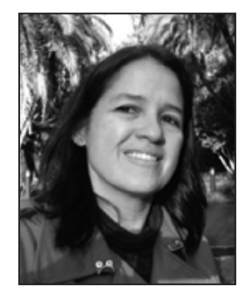

Leticia Costa-Lotufo (Leca) recently moved to University of São Paulo, where she holds an associate professor position. Previously, she was a professor at Federal University of Ceara, Fortaleza, Ceara, Brazil from 2002 to 2015. Her lab is focused on the discovery of new anticancer compounds from Brazilian 
marine biodiversity and studies on their mechanisms of action. Recently, she started a multidisciplinary project to access marine microorganisms diversity and biotechnological potential along the Brazilian coast and islands. PhD Costa-Lotufo's activities include the supervision of undergraduate and graduate students and post-doctoral fellows. She has published book chapters, review articles and more than 210 articles in peer-reviewed journals. On 2010, PhD Costa-Lotufo was nominated as a young scientist of the Brazilian Academy of Science.

\section{References}

1. Cragg, G. M.; Grothaus, P. G.; Newman, D. J.; J. Nat. Prod. 2014, 77, 70; Crane, E. A.; Gademann, K.; Angew. Chem., Int. Ed. Engl. 2016, 55, 3882.

2. Newman, D. J.; Cragg, G. M.; Mar. Drugs 2014, 12, 255; Cragg, G. M.; Newman, D. J.; Biochim. Biophys. Acta 2013, 1830, 3670; Giddings, L. A.; Newman, D. J.; J. Ind. Microbiol. Biotechnol. 2013, 40, 1181; Butler, M. S.; Robertson, A. A.; Cooper, M. A.; Nat. Prod. Rep. 2014, 31, 1612; Demain, A. L.; Vaishnav, P.; Microb. Biotechnol. 2011, 4, 687.

3. Khazir, J.; Riley, D. L.; Pilcher, L. A.; de-Maayer, P.; Mir, B. A.; Nat. Prod. Commun. 2014, 9, 1655; Gerwick, W. H.; Fenner, A. M.; Microb. Ecol. 2013, 65, 800; Hughes, C. C.; Fenical, W.; Chem.-Eur. J. 2010, 16, 12512.

4. Blunt, J. W.; Copp, B. R.; Keyzers, R. A.; Munro, M. H.; Prinsep, M. R.; Nat. Prod. Rep. 2016, 33, 382; Blunt, J. W.; Copp, B. R.; Keyzers, R. A.; Munro, M. H.; Prinsep, M. R.; Nat. Prod. Rep. 2016, 32, 116; Hanson, J. R.; Sci. Prog. 2015, 98, 177.

5. Feitelson, M. A.; Arzumanyan, A.; Kulathinal, R. J.; Blain, S. W.; Holcombe, R. F.; Mahajna, J.; Marino, M.; MartinezChantar, M. L.; Nawroth, R.; Sanchez-Garcia, I.; Sharma, D.; Saxena, N. K.; Singh, N.; Vlachostergios, P. J.; Guo, S.; Honoki, K.; Fujii, H.; Georgakilas, A. G.; Bilsland, A.; Amedei, A.; Niccolai, E.; Amin, A.; Ashraf, S. S.; Boosani, C. S.; Guha, G.; Ciriolo, M. R.; Aquilano, K.; Chen, S.; Mohammed, S. I.; Azmi, A. S.; Bhakta, D.; Halicka, D.; Keith, W. N.; Nowsheen, S.; Semin. Cancer Biol. 2015, 35, S25; Dall'Acqua, S.; Curr. Top. Med. Chem. 2014, 14, 2272; Basmadjian, C.; Zhao, Q.; Bentouhami, E.; Djehal, A.; Nebigil, C. G.; Johnson, R. A.; Serova, M.; de Gramont, A.; Faivre, S.; Raymond, E.; Désaubry, L. G.; Front. Chem. 2014, 2, 20; Elia, G.; Fugmann, T.; Neri D.; J. Proteomics 2014, 107, 50.

6. Salvador-Reyes, L. A.; Luesch, H.; Nat. Prod. Rep. 2015, 32, 478; Tresch, S.; Plant Sci. 2013, 212, 60; La Clair, J. J.; Nat. Prod. Rep. 2010, 27, 969.

7. Alexander, M. D.; Burkart, M. D.; Leonard, M. S.; Portonovo, P.; Liang, B.; Ding, X.; Joullié, M. M.; Gulledge, B. M.; Aggen, J. B.; Chamberlin, A. R.; Sandler, J.; Fenical, W.; Cui,
J.; Gharpure, S. J.; Polosukhin, A.; Zhang, H. R.; Evans, P. A.; Richardson, A. D.; Harper, M. K.; Ireland, C. M.; Vong, B. G.; Brady, T. P.; Theodorakis, E. A.; La Clair, J. J.; ChemBioChem 2006, 7, 409.

8. Yu, W. L.; Guizzunti, G.; Foley, T. L.; Burkart, M. D.; La Clair, J. J.; J. Nat. Prod. 2010, 73, 1659.

9. Hughes, C. C.; MacMillan, J. B.; Gaudêncio, S. P.; Fenical, W.; La Clair, J. J.; Angew. Chem., Int. Ed. Engl. 2009, 48, 728.

10. Hughes, C. C.; MacMillan, J. B.; Gaudêncio, S. P.; Jensen, P. R.; Fenical, W.; Angew. Chem., Int. Ed. Engl. 2009, 48, 725.

11. Hughes, C. C.; Fenical, W.; J. Am. Chem. Soc. 2010, 132, 2528.

12. Hughes, C. C.; Yang, Y. L.; Liu, W. T.; Dorrestein, P. C.; La Clair, J. J.; Fenical, W.; J. Am. Chem. Soc. 2009, 131, 12094.

13. Hughes, C. C.; Prieto-Davo, A.; Jensen, P. R.; Fenical, W.; Org. Lett. 2008, 10, 629.

14. Hughes, C. C.; Kauffman, C. A.; Jensen, P. R.; Fenical, W.; J. Org. Chem. 2010, 75, 3240.

15. Trzoss, L.; Fukuda, T.; Costa-Lotufo, L. V.; Jimenez, P.; La Clair, J. J.; Fenical, W.; Proc. Natl. Acad. Sci. USA 2014, $111,14687$.

16. Álvarez-Micó, X.; Rocha, D. D.; Guimarães, L. A.; Ambrose, A.; Chapman, E.; Costa-Lotufo, L. V.; La Clair, J. J.; Fenical, W.; ChemBioChem 2015, 16, 2002.

17. Alvarez-Mico, X.; Jensen, P. R.; Fenical, W.; Hughes, C. C.; Org. Lett. 2013, 15, 988.

18. Jensen, P. R.; Gontang, E.; Mafnas, C.; Mincer, T. J.; Fenical, W.; Environ. Microbiol. 2005, 7, 1039; Jensen, P. R.; Mincer, T. J.; Williams, P. G.; Fenical W.; Antonie van Leeuwenhoek 2005, 87, 43.

19. Pan, E.; Jamison, M.; Yousufuddin, M.; MacMillan, J. B.; Org. Lett. 2012, 14, 2390; Zurwerra, D.; Wullschleger, C. W.; Altmann, K. H.; Angew. Chem., Int. Ed. Engl. 2010, 49, 6936.

20. Takayama, Y.; Yamada, T.; Tatekabe, S.; Nagasawa, K.; Chem. Commun. 2013, 49, 6519; Reddy, P. V.; Jensen, K. C.; Mesecar, A. D.; Fanwick, P. E.; Cushman, M.; J. Med. Chem. 2012, 55, 367; Reddy, P. V.; Banerjee, B.; Cushman, M.; Org. Lett. 2010, 12, 3112 .

21. Bonello, T. T.; Stehn, J. R.; Gunning, P. W.; Future Med. Chem. 2009, 1, 1311; Jockusch, B. M.; Murk, K.; Rothkegel, M.; Rev. Physiol., Biochem. Pharmacol. 2007, 159, 131.

22. Fürstner, A.; Kirk, D.; Fenster, M. D.; Aïssa, C.; de Souza, D.; Müller, O.; Proc. Natl. Acad. Sci. U.S.A. 2005, 102, 8103; Helal, M. A.; Khalifa, S.; Ahmed, S.; J. Chem. Inf. Model. 2013, 53, 2369.

23. Reinhardt, U.; Lotze, J.; Mörl, K.; Beck-Sickinger, A. G.; Seitz, O.; Bioconjugate Chem. 2015, 26, 2106; Tsukiji, S.; Miyagawa, M.; Takaoka, Y.; Tamura, T.; Hamachi, I.; Nat. Chem. Biol. 2009, 5,341 .

24. Li, R.; Cheng, C.; Balasis, M. E.; Liu, Y.; Garner, T. P.; Daniel, K. G.; Li, J.; Qin, Y.; Gavathiotis, E.; Sebti, S. M.; Eur. J. Med. Chem. 2015, 90, 315; Cheng, P.; Clive, D. L.; 
Fernandopulle, S.; Chen, Z.; Chem. Commun. 2013, 49, 558; Nicolaou, K. C.; Simmons, N. L.; Chen, J. S.; Haste, N. M.; Nizet, V.; Tetrahedron Lett. 2011, 52, 2041; Kanakis, A. A.; Sarli, V.; Org. Lett. 2010, 12, 4872; Cheng, C.; Pan, L.; Chen, Y.; Song, H.; Qin, Y.; Li, R.; J. Comb. Chem. 2010, 12, 541.

25. Doi, K.; Li, R.; Sung, S. S.; Wu, H.; Liu, Y.; Manieri, W.; Krishnegowda, G.; Awwad, A.; Dewey, A.; Liu, X.; Amin, S.; Cheng, C.; Qin, Y.; Schonbrunn, E.; Daughdrill, G.; Loughran Jr., T. P.; Sebti, S.; Wang, H. G.; J. Biol Chem. 2012, 287, 10224; Pandey, M. K.; Gowda, K.; Doi, K.; Sharma, A. K.; Wang, H. G.; Amin, S.; PLoS One 2013, 8, e78570; Cheng, C.; Liu, Y.; Balasis, M. E.; Simmons, N. L.; Li, J.; Song, H.; Pan, L.; Qin, Y.; Nicolaou, K. C.; Sebti, S. M.; Li, R.; Mar. Drugs 2014, 12, 1335.

26. Doi, K.; Liu, Q.; Gowda, K.; Barth, B. M.; Claxton, D.; Amin, S.; Loughran Jr., T. P.; Wang, H. G.; Cancer Biol. Ther. 2014, $15,1077$.

27. Cheng, C.; Liu, Y.; Balasis, M. E.; Garner, T. P.; Li, J.; Simmons, N. L.; Berndt, N.; Song, H.; Pan, L.; Qin, Y.; Nicolaou, K. C.; Gavathiotis, E.; Sebti, S. M.; Li, R.; Mar. Drugs 2014, 12, 4311; Doi, K.; Gowda, K.; Liu, Q.; Lin, J. M.; Sung, S. S.; Dower, C.; Claxton, D.; Loughran Jr., T. P.; Amin, S.; Wang, H. G.; Cancer Biol. Ther. 2014, 15, 1688.

28. Eichhorn, J. M.; Alford, S. E.; Hughes, C. C.; Fenical, W.; Chambers, T. C.; Cell Death Dis. 2013, 4, e880.

29. Gontang, E. A.; Fenical, W.; Jensen, P. R.; Appl. Environ. Microbiol. 2007, 73, 3272.

30. Matsuoka, M.; Iwamoto, A.; Kitao, T.; J. Heterocycl. Chem. 1991, 28, 1445.

31. Mariño, G.; Niso-Santano, M.; Baehrecke; Kroemer, G.; Nat. Rev. Drug Discovery 2014, 15, 81.

32. Schittek, B.; Hipfel, R.; Sauer, B.; Bauer, J.; Kalbacher, H.; Stevanovic, S.; Schirle, M.; Schroeder, K.; Blin, N.; Meier, F.; Rassner, G.; Garbe, C.; Nat. Immunol. 2001, 2, 1133.
33. Porter, D.; Weremowicz, S.; Chin, K.; Seth, P.; Keshaviah, A.; Lahti-Domenci, J.; Bae, Y. K.; Monitto, C. L.; Merlos-Suarez, A.; Chan, J.; Hulette, C. M.; Richardson, A.; Morton, C. C.; Marks, J.; Duyao, M.; Hruban, R.; Gabrielson, E.; Gelman, R.; Polyak, K.; Proc. Natl. Acad. Sci. USA 2003, 100, 10931; Brauer, H. A.; D’Arcy, M.; Libby, T. E.; Thompson, H. J.; Yasui, Y. Y.; Hamajima, N.; Li, C. I.; Troester, M. A.; Lampe, P. D.; Breast Cancer Res. Treat. 2014, 144, 299.

34. Bancovik, J.; Moreira, D. F.; Carrasco, D.; Yao, J.; Porter, D.; Moura, R.; Camargo, A.; Fontes-Oliveira, C. C.; Malpartida, M. G.; Carambula, S.; Vannier, E.; Strauss, B. E.; Wakamatsu, A.; Alves, V. A. F.; Logullo, A. F.; Soares, F. A.; Polyak, K.; Belizario, J. E.; BMC Cancer 2015, 15, 70.

35. Shen, S. L.; Qiu, F. H.; Dayarathna, T. K.; Wu, J.; Kuang, M.; Li, S. S. C.; Peng, B. G.; Nie, J.; Biochim. Biophys. Acta 2011, $1812,703$.

36. Seyfried, T. N.; Flores, R. E.; Poff, A. M.; D’Agostino, D. P.; Carcinogenesis 2014, 35, 515; Hanahan, D.; Weinberg, R. A.; Cell 2011, 144, 646.

37. Chiaradonna, F.; Moresco, R. M.; Airoldi, C.; Gaglio, D.; Palorine, R.; Nicotra, F.; Messa, C.; Alberghina, L.; Biotechnol. Adv. 2012, 30, 30; Zhang, J. Y.; Zhang, F.; Hong, C. Q.; Giuliano, A. E.; Cui, X. J.; Zhou, G. J.; Zhang, G. J.; Cui, Y. K.; Cancer Biol. Med. 2015, 12, 10.

38. Granchi, C.; Fancelli, D.; Minutolo, F.; Bioorg. Med. Chem. Lett. 2014, 24, 4915; Song, Y.; Luo, Q.; Long, H.; Hu, Z.; Que, T.; Zhang, X.; Li, Z.; Wang, G.; Yi, L.; Liu, Z.; Fang, W.; Qi, S.; Mol. Cancer 2014, 13, 65.

Submitted: February 19, 2016 Published online: May 10, 2016

FAPESP has sponsored the publication of this article. 